\title{
The value of community technology workers for LPG use: A pilot in Shirati, Tanzania
}

\author{
Annelise Gill-Wiehl ${ }^{1,3,4^{*}}$, Sara Sievers ${ }^{3,4}$ and Daniel M. Kammen ${ }^{1,2}$
}

\begin{abstract}
Background: Sustainable Development Goal (SDG) 7 calls for the adoption and continued use of clean-burning stoves by the 2.9 billion people relying on unclean fuels (both solid biomass and kerosene). However, to date, the clean cooking literature has found low rates of efficient stove adoption and continued use. This paper presents the application of a public health community engagement model to the use of clean cooking fuels. We implemented a pilot study with Community Technology Workers (CTWs) as a means to overcome maintenance, education, and behavioral barriers to clean fuel use in rural Tanzania.
\end{abstract}

Methods: The intervention was a free 6 kg Liquified Petroleum Gas (LPG) cylinder and stove coupled with education from a local technically trained CTW on LPG use. We evaluated the training, work, and impact of a CTW on LPG use on 30 randomly selected households from two villages in a rural district of Tanzania over a 1-year period. After an initial baseline survey, technically trained local CTWs educated the households on safe LPG use and conducted 34 follow up surveys over the next year on their cooking fuel use. Additionally, we conducted qualitative interviews with all households and a focus group with six of the households.

Results: The results from the mixed methods approach show that $80 \%$ of families $(n=24)$ consistently refilled their LPG cylinders and $\sim 40 \%$ of households exclusively used LPG. Households reported appreciating the CTWs'visits for providing education and maintenance support, giving them confidence to use LPG safely, reminding them to save for their cylinder, and providing a community driven effort to use clean fuel.

Conclusions: The findings demonstrate the feasibility of this type of community infrastructure model to promote and facilitate consistent LPG use, but suggest the need to couple this local support with financial mechanisms (e.g., a microsavings program). This model could be a mechanism to increase LPG use, particularly in rural, low-income areas.

Keywords: Clean cooking, Community infrastructure, Sustainable development, LPG, Community technology worker

*Correspondence: agillwiehl@berkeley.edu

${ }^{1}$ Energy and Resources Group, University of California, 345 Giannini Hall, Berkeley, CA 94720, USA

Full list of author information is available at the end of the article

(c) The Author(s) 2022. Open Access This article is licensed under a Creative Commons Attribution 4.0 International License, which permits use, sharing, adaptation, distribution and reproduction in any medium or format, as long as you give appropriate credit to the original author(s) and the source, provide a link to the Creative Commons licence, and indicate if changes were made. The images or other third party material in this article are included in the article's Creative Commons licence, unless indicated otherwise in a credit line to the material. If material is not included in the article's Creative Commons licence and your intended use is not permitted by statutory regulation or exceeds the permitted use, you will need to obtain permission directly from the copyright holder. To view a copy of this licence, visit http://creativecommons.org/licenses/by/4.0/. The Creative Commons Public Domain Dedication waiver (http://creativeco mmons.org/publicdomain/zero/1.0/) applies to the data made available in this article, unless otherwise stated in a credit line to the data. 


\section{Background}

Sustainable Development Goal (SDG) 7 calls for the adoption and continued use ${ }^{1}$ of clean-burning stoves by the 2.9 billion people relying on unclean fuels ${ }^{2}$ including both biomass and kerosene [1]. Universal access to clean cooking fuel would help prevent up to 2.3 million annual untimely deaths that are attributed to household air pollution (HAP) [2] - a toll that disproportionately affects women and children - and reduce carbon emissions [3, 4]. In Tanzania, 96\% of the population [5], rely on polluting or "unclean" fuels. The combustion byproducts from polluting fuels are harmful for human health as particulate matter (PM) is retained in the lungs and is linked to respiratory infections, chronic obstructive pulmonary disease (COPD), and lung cancer. Overcoming barriers to clean fuel adoption and continued use is critical for helping to prevent these illnesses and untimely deaths.

The UN Sustainable Energy For All Initiative launched the Global Liquified Petroleum Gas Partnership (GLPGP) under the premise that liquified petroleum gas (LPG) was the preferred cooking solution for the next 15-20 years [6]. LPG is a byproduct of oil and natural gas refining and meets the World Health Organization's Tier 4 standards for thermal efficiency, carbon monoxide $(\mathrm{CO})$ emissions, fine PM emissions, safety, and durability. LPG has also been shown to have a lower Global Climate Change Potential than charcoal and lower black carbon emissions than firewood [7] and is in global surplus [6]. Modeling has also shown that even partial LPG or fossil fuel cooking fuel adoption and continued use could prevent 1.3 million deaths annually across sub-Saharan Africa [8].

Given the health and climate benefits of a transition, several low and middle-income countries have created LPG initiatives and set LPG targets. The largest LPG initiative has been India's Pradhan Mantri Ujjwala Yojana (PMUY) which provided women from below-the-poverty-line (BPL) households as of 20181600 Rs ( 22 USD) to purchase an LPG connection and an optional loan of 1500Rs ( 20 USD) to cover the cost of the stove and the first cylinder refills [9]. This 2016 initiative had reached 57 million households as of 2018 and was introduced on

\footnotetext{
${ }^{1}$ We define adoption as the initial uptake of the technology (i.e., deciding to purchase the technology) and continued use as the long-term usage of the technology. In this study, we provide and cover the cost of the technology, and thus we evaluate only continued use.

2 The World Bank's Energy Sector Management Program (ESMAP) defines clean cookstoves as "cookstoves that produce significantly less household air pollution than traditional three-stone open-fire stoves and meet a specified emissions standard" [47]. However, we will explicitly refer to fuels or cookstoves as "clean" only if they meet the WHO's air pollution limits of $<35$ $\mu \mathrm{g} / \mathrm{m}^{3}$ Particulate Matter and $<7 \mathrm{mg} / \mathrm{m}^{3}$ Carbon Monoxide.
}

top of India's LPG subsidy which has been in place since the 1970s [10, 11]. In Africa, Cameroon, in addition to subsidizing LPG, created an LPG Masterplan with the GLPGP which aims to have $58 \%$ of the population using LPG as a primary cooking fuel source by 2035 . Rwanda set an LPG adoption target of $40 \%$ of the population by 2024 [12]. Ghana's 2015 Sustainable Energy for All Action Plan aimed at increasing LPG use by 2020 , although in 2020 , only $22.3 \%$ of the population was using LPG [13].

Tanzania, the country in which our study took place, announced in 2015 a goal to increase the population with access to modern cooking fuels to greater than $75 \%$ by 2030; however this goal is not exclusive to LPG use [6]. In 2008, Tanzania removed the import duties and value added tax (VAT) on LPG but does not subsidize it. Despite these goals, according to the 2017-2018 Tanzanian Household Budget Survey, only $8.1 \%$ and 0.4 of the urban and rural populations respectively in Tanzania use LPG as a primary fuel [14]. This low rate of LPG use is not unique to Tanzania as LPG programs face common barriers. Previous LPG studies have provided the stove for free, provided subsidies, or provided micro loans with payment schedules, and still found low rates of adoption and continued use [15-18]. This suggests that the initial startup cost is not the only barrier to adoption and consistent use.

The evaluations of various LPG programs have elucidated the need for education, information, and maintenance support. LPG rollouts in India, Indonesia, South Africa, Sudan, Mozambique, and Nicaragua found that proper education on LPG safety and maintenance was necessary as was the provision of cooking demonstrations and instructions on how to make the traditional foods [19-23].

Community involvement has often been suggested as a way to mitigate these barriers. To increase LPG adoption, studies have argued to integrate community perspectives [24], to identify local early adopters [17], and to hold community cooking demonstrations [25]. The literature speaks to the viability of community engagement to increase LPG adoption, but also suggests that it is not sufficient at the current levels being pursued.

Based on of this literature, our research hypothesizes that providing increased training, safety information, maintenance support, and local mentors for LPG could result in higher rates of continued use.

\section{Community health workers}

To triangulate the rationality of this theory of change, we looked for analogies in other international development fields that overcame barriers to behavior change during community transitions. Specifically, our research focused on the literature on Community Health Workers (CHW), 
local workers who link their underserved communities to health systems, improving health outcomes [26]. Community Health Workers were implemented at the village level to provide individual care that was both effective, culturally appropriate, and cost effective. The World Health Organization (WHO) defines CHWs as "members of the communities where they work, [who are] selected by the communities, answerable to the communities for their activities, [and are] supported by the health system, but not necessarily a part of the organization, and have shorter training than professional workers" [27]. Tanzania has attempted to expand its national CHW programming and has deployed different types of CHWs who received various trainings, held different responsibilities, and faced a multitude of program challenges [28-30].

Observing the range and success of Tanzanian CHW programs, our project considered the model for the continued use of gas stoves to achieve clean cooking. Although CHWs have been used in cook stove programs in the past [31], USAID warns that CHWs are overworked, limiting their ability to complete all their tasks and decreasing their effectiveness at improving the health of individuals in low and middle income communities [32]. Integrating cooking assistance, or any other technical assistance, into the CHW role could compromise their success in improving the health outcomes that they currently address. Therefore, we investigated the creation of another trained worker, a Community Technology Worker (CTW), in parallel with Tanzania's CHW program. This study addresses the feasibility of the CTW to provide support for LPG use. We define the CTWs role within the specific application for LPG use, however, this role could ultimately be expanded to more technologies in rural areas.

\section{Definition of a CTW}

CTWs provide vital local infrastructure for technology adoption and use in rural villages. Technology infrastructure is as equally fragmented and weak as the health systems in many developing countries. The role and responsibility of the CTW was built off the duties of a CHW. The study defines a CTW as an individual with background knowledge and local expertise who has strong ties to a specific community to which they will be assigned. In this pilot study, we chose LPG as the technology; however, this model could be applied to other technologies. CTWs are technically trained by a local LPG company on LPG use and safety features.

After their training, CTWs assist households to adopt LPG by delivering a $6 \mathrm{~kg}$ LPG cylinder and burner that the pilot study provided, ${ }^{3}$ training the family on use and safety measures, and navigating any repairs. They are a constant resource about the technology, maintenance, and optimization of welfare acquired from the technology. This expertise consists of, but is not limited to, evaluation of broken technology, understanding the general mechanism of the technology, understanding usual or expected maintenance, and connecting to networks for efficient replacement of parts. The workers report back detailing the households' struggles and successes in LPG use.

In order to address the array of barriers to LPG use and test the flexibility of a human centered model, this study investigated the implementation of locally trained LPG experts, CTWs, and the subsequent rates of households' LPG use. The aim was to provide a case study to aid in the formulation of holistic clean cooking policy to achieve high rates of clean fuel use. Specifically, the study attempted to answer the following research questions:

1. Do households initially adopt and continue to consume LPG within this CTW model?

2. What level of $L P G$ use (i.e., exclusive or partial use) does this model help households reach?

3. How and why do households respond (or not respond) to the CTW pilot to increase their LPG use?

4. How do households understand, view, and like the pilot?

5. What barriers remain and how could the pilot be adjusted to further meet household cooking fuel needs?

\section{Methods and materials Study site}

We conducted this pilot study in Shirati, Tanzania, a town of $\sim 50,000$ on the edge of Lake Victoria near the Kenyan border (Fig. 1A). Shirati has a tropical climate with distinct rainy and dry seasons (light rains from October to December and heavy rain from March to June). Most households engage in subsistence agriculture. Within Shirati, there are sub-villages, two of which are included in this study: Kabwana and Michire (Fig. 1B). Kabwana is a larger, electrified trading area with a regional hospital, small shops, and unofficial vendors selling vegetables, fruit, and charcoal. Michire is closer to the lake and has a smaller trading post without grid electrification (some shops have single panel solar). Households can

\footnotetext{
${ }^{3}$ In this pilot study, the LPG cylinder and burner were provided to the household for free, while the household was responsible for the refill cost. The CTW is neither responsible for the upfront cost of the cylinder and stove nor the refill cost.
} 

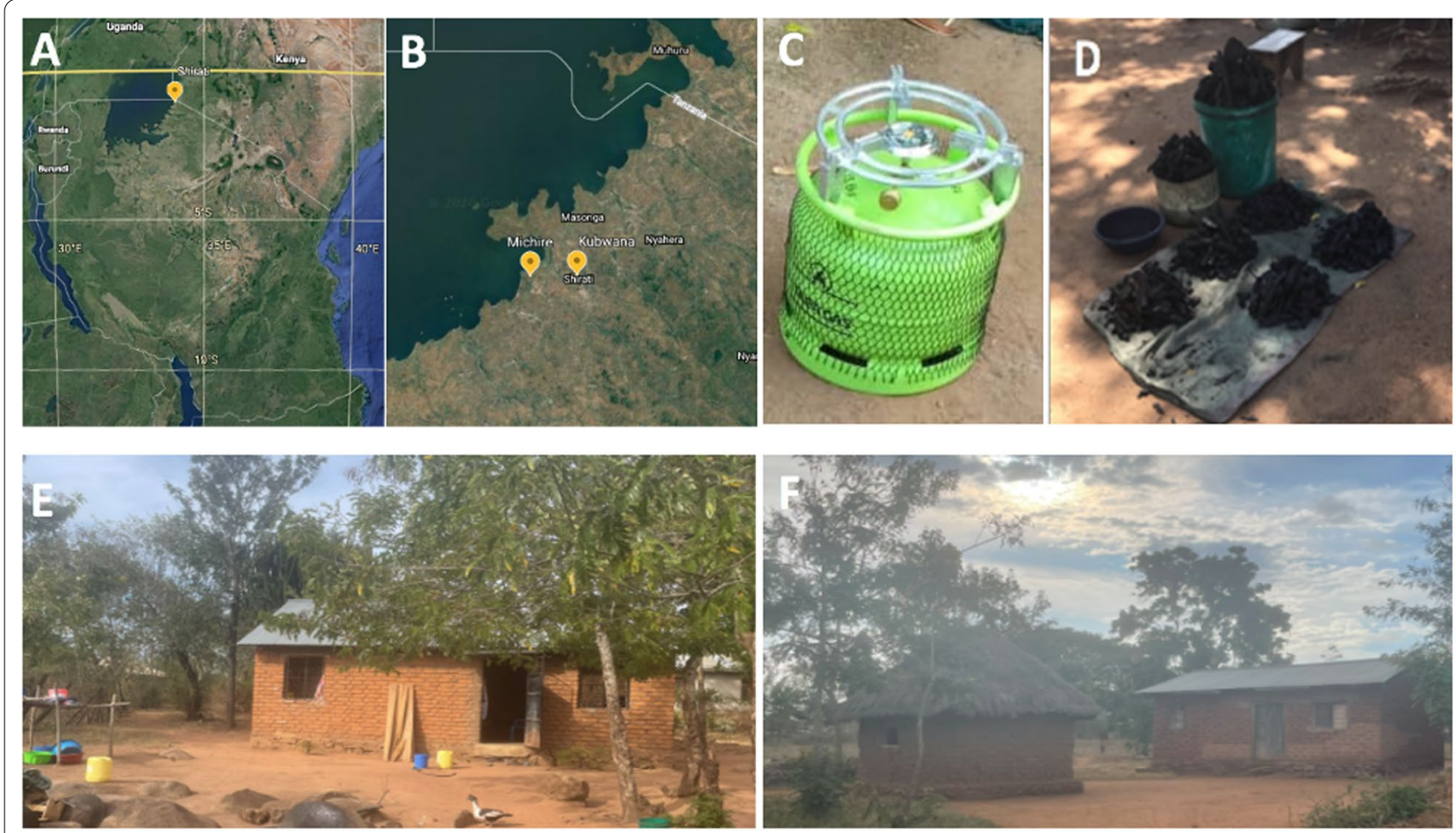

Fig. 1 A depicts Shirati within the Country of Tanzania. B Identifies the villages of Michire and Kabwana within Shirati and in relation to the Tanzanian and Kenyan border. C The intervention package of a $6 \mathrm{~kg} \mathrm{LPG} \mathrm{cylinder,} \mathrm{burner,} \mathrm{and} \mathrm{stove} \mathrm{plate.} \mathrm{D} \mathrm{Charcoal} \mathrm{for} \mathrm{sale} \mathrm{at} \mathrm{the} \mathrm{trading} \mathrm{post,}$ which can be found both in Kabwana and Michire $\mathbf{E}$ A typical home in Michire $\mathbf{F}$ A typical home in Michire

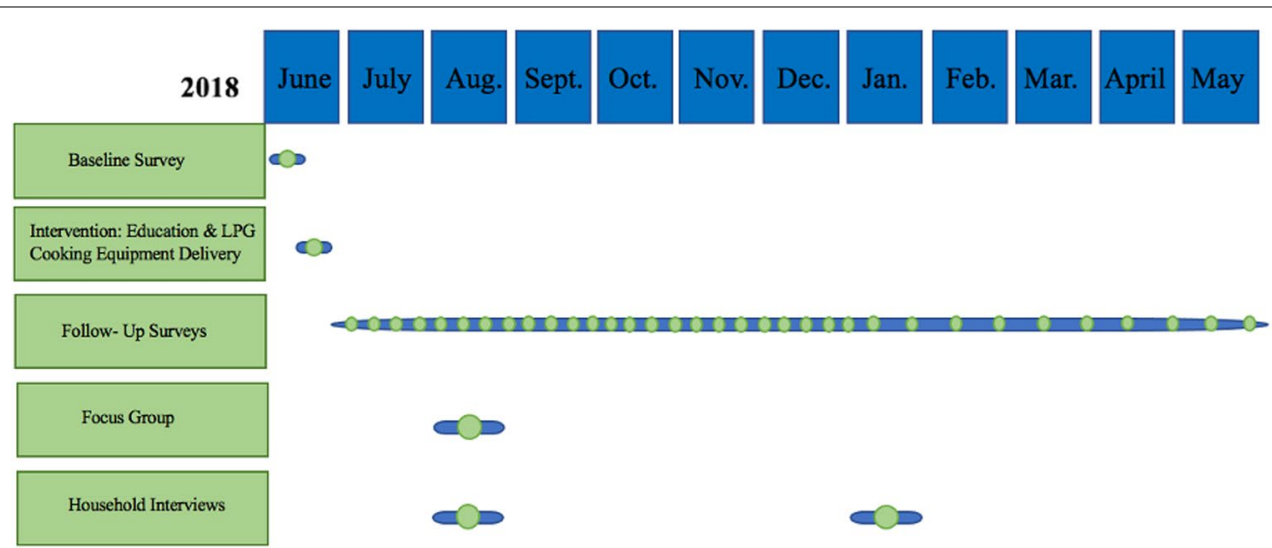

Fig. 2 This figure depicts the timeline of the methodology. A baseline energy survey was conducted in June 2018. The treatment of the $6 \mathrm{~kg}$ LPG cylinder and burner with education from the Community Technology Worker (CTW) started in June of 2018. The CTW then visited the households 34 times conducting follow-up surveys each visit throughout May of 2019. With 6 randomly selected households, we held a focus group in August of 2018. We also conducted in-depth interviews with each household in both August of 2018 and January of 2019

purchase charcoal at trading posts in both sub-villages (Fig. 1D). Since Michire is a largely wooded area, households mostly collect firewood for free. Kabwana is more urban and firewood is only collected within individuals' yards. In Kabwana, women and children have to walk far distances to obtain free firewood. There is no LPG filling station in Shirati, and thus households are able to exchange (or refill) their empty cylinder for a full cylinder at retail points in Kabwana and a neighboring sub-village, Obwyere. 


\section{Study design and intervention}

Our study invited 30 households (15 from Kabwana and 15 from Michire) to participate in a yearlong pilot (June 2018-May 2019) that consisted of the intervention of a $6 \mathrm{~kg}$ LPG cylinder and burner and weekly visits from a CTW who would track their LPG and biomass use. The study provided each household with a free $6 \mathrm{~kg}$ LPG cylinder and burner (Fig. 1C), but it was the household's responsibility to refill the cylinder $(\sim 10$ USD per refill of the $6 \mathrm{~kg}$ cylinder). After collecting a baseline energy survey, the CTW trained the household on how to use the stove and provided additional safety and maintenance information. The CTW trained households to safely check for gas leaks, put out uncontrolled flames on the burner, and protect against improper use accidents. The CTW then visited the household weekly to encourage LPG use and conduct a follow-up survey on their LPG, firewood, and charcoal use and expenditure (see section on Data Collection: Surveys). We also conducted two rounds of interviews with all households and a focus group with six households. Figure 2 depicts the timeline of the methodology.

\section{Sampling strategy}

Households were randomly chosen by approaching every fourth house, since the most recent Tanzanian Census was in 2012. The only additional household selection criterion was that the household could not already use LPG. However, this was not a limiting criterion as only one approached household already was using LPG. We therefore did not include this household in the study. No households refused to participate.

\section{CTW recruitment and training}

We recruited two female CTWs, based on the requirements that they be trustworthy, highly respected, interested in community development projects, and available for the year-long study. With a representative of a local LPG company, Mihan Gas Ltd., we trained the CTWs on safe LPG stove and fuel use, including maintenance.

\section{Data collection}

\section{Surveys}

In June of 2018, we obtained informed consent and conducted baseline energy surveys with each of the 30 households (See Additional file 1: Appendix A) to collect information on socio-demographics and energy consumption and expenditure. The survey captured quantity used and cost information on all cooking fuels (primary, secondary, etc.), grid electricity, generators, solar home systems, and solar lanterns. A week after the initial training and the LPG cooking equipment delivery, the CTW returned to check-in with the family and conduct a shorter survey to gauge gas/charcoal/firewood use, stove issues, and report any problems or concerns to adopting gas (Additional file 1: Appendix B). The CTW visited weekly throughout 2018 and transitioned to biweekly starting in 2019. They conducted a total of 34 of the same follow up survey, with data collection ending in May 2019. All quantitative data from the surveys were exported from Qualtrics and analyzed in Microsoft Excel and R.V.3.6.2 (R Foundation for Statistical Computing, Vienna, Austria).

Cooking fuel use was self-reported through these surveys. We utilized meals cooked as a proxy for energy consumption. All households reported cooking three meals per day, and thus these categories were defined for $0 / 3$ meals cooked with LPG (No LPG Use), 1/3 meals cooked with LPG (Minority LPG Use), 2/3 meals cooked with LPG (Majority LPG Use), and 3/3 meals cooked with LPG (Exclusive LPG use). The number of meals cooked with LPG was calculated from the quantitative survey that asked how many meals the household prepared each day, and of those meals how many were made with LPG. The households using LPG as a majority or minority fuel were using both LPG and biomass (stacking the fuels). Therefore, the CTW would inquire exactly what they prepared the day before and with which cooking fuel to determine the proportion of meals with each fuel type. Exclusive LPG use and no LPG use was determined from the quantitative survey that asked about continued biomass expenditure and if the household was refiling their cylinder. In Additional file 1: Appendix D, we also include analysis without differentiating between Majority or Minority users, but rather group these households together as Stacking LPG Users.

Throughout study, the first author monitored data collection on a weekly basis and held weekly meetings to discuss research findings to ensure data quality. We ensured that the two women did not have any relatives in the households in the study or other conflicts of interest.

\section{Interviews and focus groups}

Over the course of the study, we conducted two rounds of hour-long individual interviews with all households and the two CTWs (Additional file 1: Appendix C). The first round was conducted 2 months into the study and investigated perception of the pilot, their comfort level with the $\mathrm{CTW}$, the challenges to adopting gas, and areas for pilot improvement and adjustment. After 6 months, a second round was conducted to investigate social pressure to refill and how often the CTW should visit each household. While the first author speaks Swahili, the interviews were conducted with a help of a translator to ensure clear communication. These interviews were recorded, transcribed and translated in the days after the 
Table 1 Household demographic and baseline energy information of the 30 households

\begin{tabular}{|c|c|c|c|c|}
\hline & $\begin{array}{l}\text { Overall } \\
\text { Mean (s.d.) }\end{array}$ & $\begin{array}{l}\text { Kabwana } \\
\text { Mean (s.d.) }\end{array}$ & $\begin{array}{l}\text { Michire } \\
\text { Mean (s.d.) }\end{array}$ & $\begin{array}{l}\text { Mara Region } \\
\text { Mean (s.d.) }\end{array}$ \\
\hline \multicolumn{5}{|l|}{ Panel A: Demographic } \\
\hline Household Size (Individuals) & $6.1(2.2)$ & $6.7(2.1)$ & $5.3(2.2)$ & 5.9 \\
\hline Age (Years) & $48(18.72)$ & $43.9(17.6)$ & $51.4(19.6)$ & $47(14.8)$ \\
\hline Age Range (Years) & {$[21,90]$} & {$[23,90]$} & {$[21,85]$} & {$[13,97]$} \\
\hline Female Main Cook & $97 \%$ & $100 \%$ & $93 \%$ & \\
\hline \multicolumn{5}{|l|}{ Occupation } \\
\hline Cares for Home and Children & $23 \%$ & $13 \%$ & $27 \%$ & a \\
\hline Farmer & $47 \%$ & $53 \%$ & $40 \%$ & \\
\hline Business & $30 \%$ & $33 \%$ & $33 \%$ & \\
\hline \multicolumn{5}{|l|}{ Marital status } \\
\hline Single & $17 \%$ & $20 \%$ & $13 \%$ & $6 \%$ \\
\hline Married & $60 \%$ & $60 \%$ & $60 \%$ & $70 \%$ \\
\hline Divorced & $0 \%$ & $0 \%$ & $0 \%$ & $8 \%$ \\
\hline Widow & $23 \%$ & $20 \%$ & $27 \%$ & $16 \%$ \\
\hline \multicolumn{5}{|l|}{ Education level } \\
\hline No Education & $13 \%$ & $7 \%$ & $20 \%$ & $21 \%$ \\
\hline Primary & $67 \%$ & $80 \%$ & $53 \%$ & $62 \%$ \\
\hline Secondary & $17 \%$ & $7 \%$ & $27 \%$ & $12 \%$ \\
\hline University & $3 \%$ & $7 \%$ & $0 \%$ & $5 \%$ \\
\hline \multicolumn{5}{|l|}{ Panel B: baseline energy usage } \\
\hline \multicolumn{5}{|l|}{ Grid } \\
\hline Connected to the National Grid & $23 \%$ & $20 \%$ & $27 \%$ & $20.8 \%$ \\
\hline Cost per Month (USD/month) & $5.1(3.7)$ & $3.8(3.8)$ & $5.9(4.3)$ & $1.2(1.2)$ \\
\hline \multicolumn{5}{|l|}{ Solar } \\
\hline Panels & $17 \%$ & $20 \%$ & $13 \%$ & $26.6 \%$ \\
\hline Solar Lanterns & $43 \%$ & $33 \%$ & $53 \%$ & $31 \%^{b}$ \\
\hline Cost per Panel (USD/panel) & $60.3(42.8)$ & $73.9(67.6)$ & $46.7(67.6)$ & $38.0(51.2)$ \\
\hline Installation Fee (USD) & $76.0(64.6)$ & $30.4(0)$ & $121.8(0)$ & \\
\hline Kerosene for lighting & $23 \%$ & $40 \%$ & $7 \%$ & $12.3 \%^{c}$ \\
\hline Liters per Day & $0.14(0.11)$ & $0.14(0.12)$ & $0.165(0)$ & \\
\hline Cost per Day & $0.15(0.07)$ & $0.14(.07)$ & $0.21(0)$ & $0.07(0.1)$ \\
\hline Cooking fuel types & & & & Only tracked primary fuel \\
\hline Firewood Only & $33 \%$ & $13 \%$ & $53 \%$ & $72.9 \%$ \\
\hline Charcoal Only & $13 \%$ & $20 \%$ & $7 \%$ & $23.5 \%$ \\
\hline Firewood and Charcoal & $54 \%$ & $67 \%$ & $40 \%$ & N/A \\
\hline LPG & $0 \%$ & $0 \%$ & $0 \%$ & $1.4 \%$ \\
\hline \multicolumn{5}{|l|}{ Charcoal } \\
\hline Sacks per Month & $1.6(2.25)$ & $2.1(3.0)$ & $1.0(.9)$ & \\
\hline Cost per Day (USD/day) (if using charcoal) & $0.4(0.24)$ & $0.3(0.2)$ & $0.5(0.26)$ & $0.19(0.16)$ \\
\hline \multicolumn{5}{|l|}{ Firewood } \\
\hline Cost per Day (USD/day) (if purchasing firewood) & $0.52(0.26)$ & $0.41(.03)$ & $0.76(0.15)$ & $0.25(0.22)$ \\
\hline $\begin{array}{l}\text { Hours Collecting Firewood per Day } \\
\text { Source of firewood }\end{array}$ & $0.83(0.5)$ & $0.66(0.6)$ & $0.94(0.43)$ & \\
\hline Both Buying and Collecting & $37 \%$ & $33 \%$ & $3 \%$ & \\
\hline Only Collecting & $43 \%$ & $3 \%$ & $40 \%$ & \\
\hline Only Buying & $7 \%$ & $3 \%$ & $3 \%$ & \\
\hline Neither & $13 \%$ & $10 \%$ & $3 \%$ & \\
\hline
\end{tabular}


Table 1 (continued)

\begin{tabular}{|c|c|c|c|c|}
\hline & $\begin{array}{l}\text { Overall } \\
\text { Mean (s.d.) }\end{array}$ & $\begin{array}{l}\text { Kabwana } \\
\text { Mean (s.d.) }\end{array}$ & $\begin{array}{l}\text { Michire } \\
\text { Mean (s.d.) }\end{array}$ & $\begin{array}{l}\text { Mara Region } \\
\text { Mean (s.d.) }\end{array}$ \\
\hline \multicolumn{5}{|l|}{ Total expenditure on cooking fuels } \\
\hline $\begin{array}{l}\text { No Cooking Fuel Expense (i.e., only collecting firewood } \\
\text { and no charcoal use) }\end{array}$ & $27 \%$ & $0 \%$ & $53 \%$ & $20 \%$ \\
\hline $\begin{array}{l}\text { Total Cooking Fuel Expense (USD/day) (if purchasing } \\
\text { cooking fuel) }\end{array}$ & $0.68(0.4)$ & $0.73(0.3)$ & $0.57(0.4)$ & $0.32(.25)$ \\
\hline
\end{tabular}

interview. We coded by hand the interviews for emergent themes and then grouped these themes. This analysis was then conducted a second time to ensure consistency. These themes were then evaluated for frequency by participant and village. Finally, we triangulated these qualitative findings with the quantitative results to further our understanding.

Two months into the study, the CTWs and the first author held a two-hour long focus group with six of the main cooks to evaluate the pilot. Three main cooks from each village were randomly chosen to participate. In a manner similar to the interview analysis, the focus group meeting was recorded, promptly transcribed and translated with the help of a translator, analyzed for themes, and triangulated with quantitative results.

\section{Results}

\section{Household demographic results}

Table 1 provides information on household level baseline demographic characteristics and current energy use. Only one household had a main cook who was male. Household size ranged from 1 to 10 with an average of 6.1. The age range of 21-90 years demonstrates that the pilot represents both young and old cooks' response to this model. The occupation of each main cook was roughly split between caring for the home and children, farming, and business. Sixty percent of main cooks were married, while $17 \%$ were single and $23 \%$ widowed. Sixty seven percent of main cooks had finished primary school, and $13 \%$ had no education. Only $23 \%$ of the households were connected to the national grid, TANESCO. Seventeen percent and $43 \%$ relied on solar panels and lanterns for lighting respectively. No household utilized kerosene for cooking, but $23 \%$ used it for lighting.

We compare our results to the 2017-2018 Tanzanian Household Budget Survey for the Mara Region. The region has a slightly higher rate of marriage, divorce and solar use, while significantly lower rates for expenditure on electricity. The Tanzanian Household Budget Survey utilized different employment categories, but 63.72\% of female heads of households were self-employed, $14 \%$ were unemployed, never worked, or didn't know, and $17.5 \%$ were unpaid household workers.

\section{Baseline cooking fuel use and expenditure results}

In our study, 54\% of households used both charcoal and firewood for cooking, while $33 \%$ or $13 \%$ used only firewood or only charcoal respectively. The only other fuel that two individuals used was "magoonzi," a type of agricultural waste. Forty-three percent of households were only collecting firewood, while $37 \%$ were both buying and collecting firewood. Eight households, all from Michire, reported no expenditure on cooking fuel as they only collected firewood for free. However, 22 households purchased cooking fuel. On average, households who purchased fuel spent $0.68 \mathrm{USD} /$ day on cooking fuel. We note that this cost per day does not include the opportunity cost of time for those collecting. From the Tanzanian Household Budget Survey, we determined the percentage of households purchasing fuel and the total cost of cooking based off reported expenditure on gas, charcoal, firewood, coal, and kerosene. The Mara region has slightly lower rates for expenditure on kerosene, charcoal, and firewood for those households purchasing cooking fuel. This is expected as this average from the Tanzanian Household Budget Survey captures the entire region, including more remote areas than Kabwana and Michire in Shirati. The percentage of households that purchase fuel is roughly the same between our sample and the regional average, and thus those purchasing throughout the Mara region must be supplementing purchased fuel with collected fuel which the survey does not account for. The Tanzanian Household Budget Survey in addition did not measure the time spent collecting firewood or cooking fuel consumption values. 


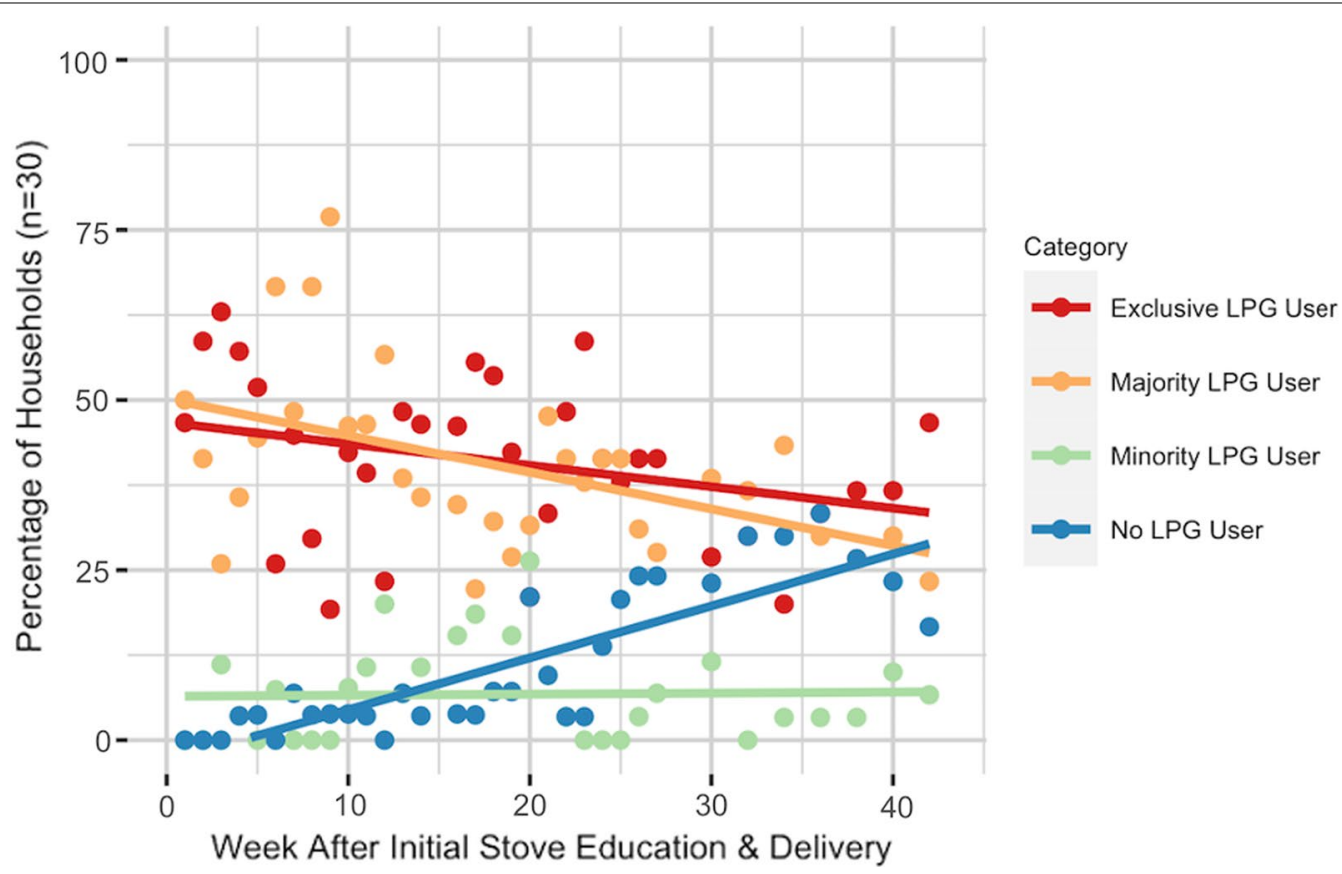

Fig. 3 Trends in Exclusive LPG Users, Majority LPG Users, Minority LPG Users, and No LPG Users over the course of the study (June 2018-May 2019). These results revealed that exclusive and majority use of LPG steadily declined throughout the study period, while abandonment of LPG (No LPG User) increased throughout the study; however, the percentage of minority LPG users stayed relatively constant. All households reported cooking three meals per day, thus these categories were defined as 0/3 (No LPG Use), 1/3 (Minority LPG Use), 2/3 (Majority LPG Use), 3/3 LPG use (Exclusive LPG Use). The number of meals cooked with LPG was calculated from the quantitative survey that asked how many meals the household was cooking each day, and of those, for how many did the household use LPG. Exclusive LPG use and no LPG use were determined from the quantitative survey that asked about continued biomass expenditure and whether the household was refiling their cylinder

\section{Cooking patterns}

All households in the study reported preparing three meals per day, consisting typically of tea and ugi (a porridge) in the morning and a lunch and dinner of ugali (a traditional dish of corn flour and boiled water), dagaa (small fish), and vegetables. Occasionally, households prepare rice, larger fish, potatoes, beans, and makande (a corn and bean mixture). Households reported being unable to prepare beans with LPG; however, the CTW explained that if you soak the beans overnight then the beans will cook much faster. Households that did cook beans, only reported making them once a week. No household mentioned using LPG to reheat meals. The use of hotpots is common to keep food warm throughout the day. Households complained that they were unable to prepare larger meals with LPG.

\section{Refilling}

The small sample allowed us to follow individual households. Over the course of the year, 24 families out of the 30 consistently refilled the gas cylinder each month (80\%). Three households had stopped refilling after 6 months of consistent refilling due to sickness, loss of a parent (who provided the income), and loss of a business (10\%). The remaining three families inconsistently refilled due to economic setbacks from school fees or decreased business revenue $(10 \%)$. This resulted in a lag time between their refills, but the households eventually resumed refilling the gas cylinder. Initially, without a meter, households struggled to know when the cylinder would run out. Over time, households were able to estimate how long the cylinder would last, which reduced the gap between refills. Over the course of the study, among the 24 families that consistently refilled their gas cylinders, the households averaged $1.2 \mathrm{~kg}$ of LPG per person per month (Range $0.4-3 \mathrm{~kg} /$ person/month SD: 0.6 ).

\section{Exclusive use, mixed use, no use}

Figure 3 depicts the temporal trends (from the time of intervention) of the percentage of families who were exclusive LPG users, majority LPG users, minority LPG users, and those who did not use any LPG. Examining the trend lines throughout the study revealed that exclusive LPG use and majority LPG use were the most common categories. Exclusive LPG use and majority LPG use were higher initially in the first few weeks of the study, but slowly decreased over time. Contrastingly, No LPG use increased in the latter 6 months of 


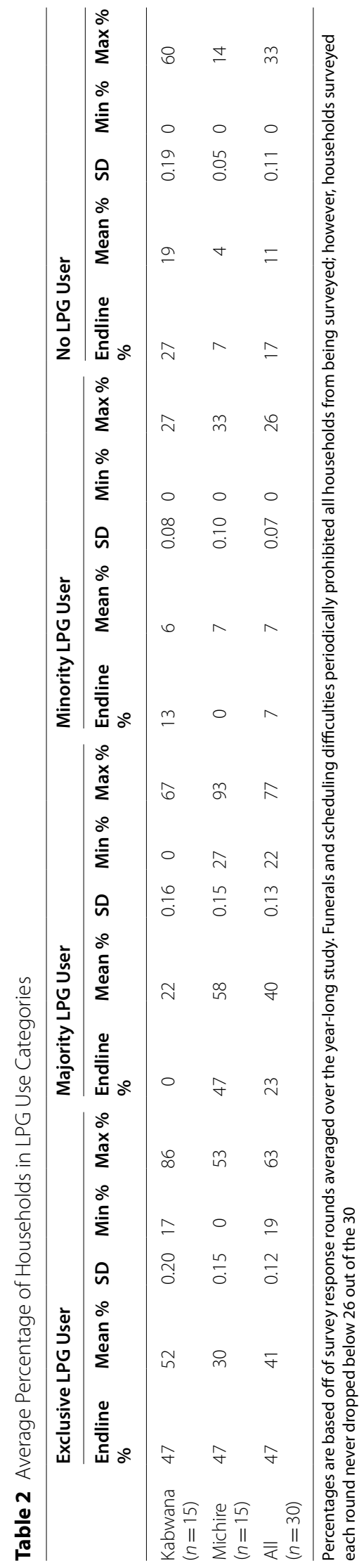


the study. However, minority LPG users were stable throughout the study period (Fig. 3). On average, $41 \%$ of households were exclusive users, $40 \%$ of households were using LPG for the majority of meals, only $7 \%$ were using LPG for the minority of meals, and $11 \%$ were not using any LPG (Table 2). At the endline, $47 \%$ of households were exclusive users, $23 \%$ of households were using LPG for the majority of meals, only $13 \%$ were using LPG for the minority of meals, and $17 \%$ were not using any LPG (Table 2). We note that there was high variability week to week for each category; therefore, we emphasize the trends throughout the study period, rather than any specific week's average. Overall, we find that although relatively high throughout the study period, rates of exclusive LPG use declined over the study period and rates of no LPG use increased.

Interviews revealed that these trends were largely due to liquidity constraints, the LPG refill is a lump sum compared to the small daily purchases of firewood or charcoal. However, households noted that the CTW visits were important reminders to save. Additional investigation at the village level offered further explanation of these trend lines.

\section{Village comparison}

LPG cylinders can be exchanged ${ }^{4}$ at retail points in Kabwana or a nearby village, Obwere, which has the largest trading post in Shirati. Therefore, households in Michire faced a longer distance to refill their cylinder. All households were within 2 miles of an LPG retail location.

On average in Michire, $30 \%$ of households were exclusive LPG users, $58 \%$ were majority LPG users, $7 \%$ were minority LPG users, and only $4 \%$ used no LPG (Table 2 ). Michire had consistently higher rates of partial use and consistent fuel stacking than Kabwana (Table 2). Contrastingly, Kabwana had higher rates of exclusive use (52\%), lower rates of majority LPG use (22\%), similar minority LPG use (6\%), and higher rates of no LPG use (19\%) (Table 2). The majority of households in Kabwana used LPG exclusively or not at all, while the households in Michire consistently stacked their cooking fuels. The endline values for both villages support these results. At endline in Kabwana, 47\% of households were using LPG exclusively, $0 \%$ were majority users, $13 \%$ were minority users, and $27 \%$ were not using any LPG. At endline in Michire, $47 \%$ of households were exclusively LPG users, $58 \%$ were majority LPG users, $0 \%$ were minority users, and $7 \%$ were not using any LPG.

\footnotetext{
${ }^{4}$ There is no filling station in Shirati, and thus we define refiling the LPG cylinder as exchanging an empty cylinder for a full cylinder at these retail points.
}

Qualitative interviews revealed that Michire's proximity to wooded areas and therefore free biomass led to continued fuel stacking. Despite access to free biomass, Michire households reported that the CTW reminded them and encouraged them to prioritize LPG use. In Kabwana, households reported school fees, hospital visits, and other expenses unexpectantly arose and drained the funds that the CTW encouraged them to save. However, the CTW in Kabwana noted that she would meet with troubled households and create a plan to help them refill again.

\section{Boiling water}

The consistent need for sterilized water prohibited exclusive LPG use. On average throughout the entire study period, 3 households out of the entire sample $(\sim 10 \%)$ were using firewood to boil water (4 SD, 0 Min, 14 Max). The CTWs reported that households did not want to boil water with LPG, as they preferred LPG for cooking. Subsequently, the CTW educated the households on Water Guard, a purification tablet, to help eliminate biomass burning for water purification. After 10 months, no household in the pilot used biomass to boil for the remainder of the study. Therefore, at endline, no household was using firewood or charcoal for boiling water. Discussion in the focus group revealed that the CTW had taught the families techniques to rid the water of a distinct smell associated with Water Guard. Households were then able to adopt Water Guard and abandon boiling with biomass.

\section{Perceived ability to refill}

At the endline, $86.6 \%$ of families overall (80\% in Kabwana and $93.3 \%$ in Michire) reported feeling confident about being able to refill their cylinder. On average throughout the study period, $93.7 \%$ of families $(87.9 \%$ in Kabwana and $97.4 \%$ in Michire) reported feeling confident in their ability to refill. The families did not report experiencing an overbearing economic burden in refilling the stove. The follow-up survey taken around the Christmas holidays (the 26th follow up survey) reported the lowest levels of household's confidence in their ability to refill the cylinder at 50\%, 93.3\%, and 73\% for Kabwana, Michire, and overall, respectively. Interviews revealed that this was because households often have extra expenses around the holidays. Households reported that the CTW increased their confidence in their ability to refill. The CTWs example and vote of confidence improved the households' perception of their capability to refill their LPG cylinder.

\section{Savings}

Our study asked if households were saving for their next cylinder and if so, how much they were saving. An LPG 
refill costs $\sim 10$ USD $(23,000 \mathrm{TSH})$ or $\sim 1.67 \mathrm{USD} / \mathrm{kg}$. Families saved on average 5.2 USD [Range: 0.5-8 USD (1500 TSH-18000 TSH)] for the refill throughout the study period. At the endline, households in Kabwana had saved 3.8 USD (8900 TSH), while households in Michire reported no savings. It is interesting to note that the families in Michire claimed they were able to save for the next cylinder, but then revealed that after the first 3 months of the study, they consistently had no amount saved. Households in both villages expressed that they wanted a more formal savings account for their LPG cylinder refill. The households that were saving for their cylinders were doing so informally at home. The reported barriers to refill were the fluctuating LPG prices and the lack of an organized mechanism for saving. Although the LPG price changes throughout the study period were minimal ( \pm 0.5 USD (1000 TSH)), this amount is substantial to low-income households. Households noted that it was hard to save that large of a lump sum compared to spending smaller sums more frequently on biomass, especially when the LPG price changes month to month. They articulated that it is often hard to set aside money for the refill when they have so many other financial demands. The interviews revealed that households appreciated the CTW visits specifically for the reminder and encouragement to save little by little.

\section{Maintenance and safety}

In total, there were 10 issues reported with the stoves, all within the first 6 months of the study. Most problems were due to defective, flimsy burners, which the CTW helped replace. Interviews revealed that the CTW provided a level of convenience and speed to minimize the number of meals cooked with unclean fuels before getting the new part. Households did not understand that they could request a free replacement from the gas company and did not know where they could purchase a new burner, as some of the refilling stations in the village did not sell them. On occasion, the CTW would re-review stove use and safety training. There were no accidents.

\section{Education}

In post household visit interviews, families stressed the importance of the education that the CTW provided on stove use and safety. Thirteen of 30 interviews expressed an appreciation for education and for the knowledge that we did not foresee as an effect of the pilot. These families appreciated learning and gaining the education about the gas stove. A woman in Michire said, "There is nothing that has passed me... I have memorized it." Women in Kabwana asked "if there were any more teachings." A woman in Michire offered "I do welcome you anytime if there is anything else that you want to teach me." They expressed that the presence of the CTW gave them confidence in LPG use and safety. The CTWs also enjoyed providing education as Michire's CTW said, "My favorite part of my job is teaching families how to use the stove." The CTWs felt a desire to help the community.

\section{Community involvement for LPG use and beyond}

Households noted the friendship and trust that they had built with the CTWs. Households alluded to a continued relationship with the CTW in a positive light. Many families wanted to continue and sustain the relationship with the CTW. For example, one Kabwanan woman, when asked about CTW visits, said "Come in the morning, afternoon, evening. Wake me up. There is no problem." Another woman in Michire revealed the intimacy of the pilot and the importance of proximity. When asked if she felt comfortable contacting the CTW, she responded "Yes and if she does not answer, I will send a kid to her house." The focus group reiterated the importance of the relationship between the CTW and the households. For example, one woman from Kabwana said, "We have become friends. We greet each other. You find out what the problem is, and you help. If there is a problem, we find a solution."

All families suggested the continuation or expansion of the project. They wanted to include other community members and even expand it to other topics such as electricity, HIV, orphans, and solar lights. A main cook in Michire said, "This project should not just focus on cooking." These narratives indicated the importance of community involvement in achieving any sustainable solution.

Throughout the interviews, we asked if the households would prefer text messages or phone calls instead of physical visits. Highlighting the importance of face-toface interactions, households suggested the use of phone calls for emergency situations, but implied that they may not be honest about their LPG use over the phone. Households stressed the importance of the physical visit but did note that bi-weekly visiting would be acceptable compared to weekly.

\section{Social pressure to refill?}

Finally, the interviews investigated why the households were refilling to ensure that the $\mathrm{CTW}$ was not placing an undue burden on already financially and psychologically stressed households. Families noted that they had adjusted to the gas stove and were not refilling to please the CTW, but rather refilling for their own benefit. One woman posed the question, "How can [the CTW] pressure me when the gas helps me, not the CTW?" The families discussed how the gas stove eases the work and allows them to finish cooking faster and continue 
with other activities. The majority of families claimed that it was their responsibility to refill the cylinder as it was benefiting their family. One family noted that "It is my responsibility to refill it even without being monitored because I know how valuable it is." Participants felt this "responsibility" not to the CTW, but rather to themselves.

\section{Discussion}

Previous LPG programs to date have failed to achieve high rates of consistent use, let alone exclusive use, particularly in rural areas $[16,33-35]$. These programs often fail due to an inability to address all (or even many) of the barriers to clean fuel use. Our pilot study attempted to holistically address these barriers at the household level, by leaning on a local engagement model proven effective in global health. Our results identify the CTW model as a possible mechanism to increase rates of LPG use. While this model shows the potential to reduce social and technical barriers if scaled, economic barriers such as liquidity constraints and the availability of freely collected biomass still remain, preventing universal exclusive use. However, the qualitative results reveal opportunities to pair this engagement model with other financial policies to achieve exclusive use. While comparing it to $\mathrm{CHW}$ programs, we discuss how this pilot might be funded and scaled as a potential public-private partnership (PPP), its advantages over IT solutions, and the applicability of CTWs beyond LPG.

\section{Holistic role of CTW: education, financial advising, water purification, etc}

Overall, the results revealed that households appreciated the CTW visits for providing education and maintenance support, giving them confidence to use LPG safely, reminding them to save for their cylinder, and providing a local effort to increase clean fuel use. Households are not simply financial entities, but also have educational, social, and cultural facets that shape their ultimate behavior. The CTW model leverages the strength in grassroots solutions towards clean fuel use.

The role of the CTW was holistic and engaged many aspects of the households needs including water purification. The literature confirms that water boiling is a barrier to clean fuel use [36], at times accounting for a third of all biomass collection [37]. Although the CTW's main role was to increase LPG use, households face many demands that affect the choice of fuel, and the CTW was able to adjust to help meet those needs as well.

This holistic aspect of the CTW is similar to CHWs who often work with their clients on various ailments as well as non-medical aspects that affect their ability to receive care $[26,38,39]$.

\section{Necessary, but insufficient}

Our study found high rates of exclusive LPG use compared to other LPG evaluations in Sub-Saharan Africa. An evaluation of Ghana's Rural LPG promotion program found that only $8 \%$ households were refilling after 18 months [16]. Evaluations of Cameroon's LPG Masterplan in peri-urban and rural communities in the southwest of the country revealed that in rural communities only $16 \%$ of households were using any LPG [33] and only $1.2 \%$ did all their cooking with LPG [34]. Beyond national LPG programming, a pilot of a microfinance intervention for the upfront cost of the LPG stove in Kenya found that $81.1 \%$ of participants were using multiple fuels [35]. Without income data, we are unable to speak to the relative poverty between our sample and the other studies, as income is a factor in the ability to refill. However, as all are low-middle income countries, the $\sim 80 \%$ of households continuously refilling their cylinder and $40 \%$ exclusively adopting LPG still stands out in the literature.

If we factor in the opportunity cost of the time for cooking and collecting firewood, gas becomes a more attractive option as women could use that time for economic activity. However, the pattern of LPG payment remained a challenge. The survey did not collect any direct household income information, but Tanzania reported in 2015 that the GDP per capita was 834 USD $(1,918,928 \mathrm{TSH})$ or 70 USD $(159,910 \mathrm{TSH})$ per month [40]. Fuel is therefore a large part of household expenditure. Refilling the gas stove monthly is $13 \%$ of that average monthly income. This is a large percentage of monthly income to accumulate at one time, and often the inability to save up the lump sum leads to a day or month long gap between refills [41]. Thus, the CTW could be useful in addressing affordability concerns and shortening these gaps, especially if paired with savings options, for which the households expressed a need. Households could create financial plans with the CTW to save the money they would have spent daily or weekly on firewood or charcoal towards their LPG refill. In a rural context, this could be in the form of a lock box, while urban populations may prefer a dedicated mobile account. A recent review of affordability in clean cooking called for increased research into microsavings as a tool to increase the affordability of fuel refill cost [42].

The CTW does not remove all barriers to gas use, specifically the economic aspects. However, these results suggest that a CTW does help mitigate a wide range of barriers through education and maintenance support. These results imply that the CTW pilot simply should adjust and continually strive for holistic programming to overcome all barriers to LPG use.

This challenge is not unique to CTWs as CHW programs do improve the health of the local communities 
they serve, but they are not a complete replacement of full-service medical care, nor can they mitigate hospital or medication fees.

\section{Funding and feasibility at scale}

This CTW model could be funded as a PPP between the government's Ministry of Energy and Minerals (or the Ministry of Health and Social Welfare) and the LPG companies. This PPP model would be very different from the funding models of $\mathrm{CHW}$ programs, where there is a clear public interest in improving health care. With CTWs, there is not always that clear public interest. However, in this case of CTWs being utilized to increase LPG use, there is rationale for some of the funding to come from the public sector as the CTW is clearly focused on activities of public interest with regard to health, the climate, and gender empowerment. However, the CTW also promotes a technology provided by a private sector firm. This local outreach model not only acts as advertising for the company, but also promotes the expansion of their markets and distribution networks. The CTW financial management model does not require that the private sector offer a new product. It stretches the private sector's business models to work with customers who consume small amounts of gas. The private sector has the challenge of supplying a dispersed customer base, while still providing the maintenance, repair, and sales support. The safety of LPG distribution networks is often also a challenge for the private sector; the CTW could provide further confidence that safety issues will not arise at the household level. The CTW could lessen the burden on the private sector, while simultaneously addressing household continued use.

Private companies should be building their own market creation, and thus should contribute to the funding of these local workers. CTWs could even become a recognized role within the companies, especially since they provide the technical training for these works. However, in the case of clean cooking, there is also a clear and urgent public interest in the adoption and continued use of clean fuel; thus, a PPP could be a compromise.

The CTW pilot itself is quite intensive with frequent visits to a small set of households and would arguably be very expensive to implement at scale. However, in this pilot study we only assigned 15 households to each CTW, conducted weekly visits, and paid CTWs a rate that included translation work and survey enumeration. The results and discussion address that these aspects could and would be adjusted in scaling this model. For example, CTWs would be paid the same rate as CHWs, CTWs could work with 50 households each, and/or the CTWs could visit weekly for a month and then adjust to monthly check-ins in combination with weekly phone calls). The range of CHW programs in Tanzania reveal how different models could be adapted based on community needs and local government budgets. Finally, the expense of the pilot could be mitigated through a public-private partnership. The health, climate, and gender implications of unclean fuel use indicate that we must pursue aggressive policy to ensure universal adoption and even more importantly continued, exclusive use.

\section{IT vs. in-person visits}

The advantage of this model for cooking over an IT-based solution (i.e., text message education or reminders) is that human workers can respond and adapt to the specific issues of the household and provide helpful advice. Cooking is particularly entrenched in cultural and social issues that pose adoption and use issues that lighting, for instance, does not. These challenges, similar to those in health care, require in-person visits to overcome these barriers as opposed to telephone conversations or text messages. Even companies like Envirofit, that pursue large scale cookstove deployment mostly through ITbased communication [43], admit that "while investing in training resources increases costs, it also increases adoption" [43]. Technology does not negate the need for a local worker to assist in the behavioral, safety, education, and maintenance issues.

Most CHW programs provide a combination of physical visits and IT outreach [26]. A few studies of CHW programs in Malawi, South Africa, and Kenya found text messages to be successful in a variety of use cases including appointment reminders, questions for physicians, and even cardiovascular disease screening [44-46]. However, the CHWs in the Kenya study stressed that these visits should be combined with in person visits [44]. To our knowledge, there are no CHW programs in Tanzania that rely only on IT outreach. Although mobile phones are pervasive even in rural communities, network issues, the inability to re-charge phones, and the expense of phone credit, may make only IT visits not as viable.

Despite this, there is a financial incentive for implementers to reduce the physical visits. Even reducing the physical visits to once a month (coupled with a weekly text message), compared to physical visit on a bi-weekly basis could cut CTW costs in half. Another pilot of this model could provide phone credit, so as not to burden the household with an additional expense, but still pursue an inexpensive alternative to an additional visit. Further research into comparison studies between a physical visiting model and a remote check in system could assist policy makers in deciding whether the financial burden of the CTW salaries was necessary to provide this support for continued use. From interviews, the fact that the CTW was from their community and the household was 
able to create a personal relationship with them proved to be very important, but further research is advised.

\section{Beyond LPG}

Based on the discussion of expanding the CTW project, this model may be most cost effective in areas where you could pair the role of this local outreach worker with other rural community needs. This model may not be as cost effective in an urban setting where IT-based solutions may suffice, but rural, traditional settings require intra-community support. As rural communities are being exposed to new technologies, the CTWs could play a wider role in supporting renewable energy technologies as well as other technologies (mobile phones, IT systems, water and waste related technologies). This local worker could also address lighting, water pumps, mini grids, etc. to holistically support rural household energy infrastructure. There is an opportunity for the CTW to play a wider role in energy access, but also development goals in general. Expanding the role of CTWs is in line with the $\mathrm{CHW}$ literature as most CHWs are trained in "promotive, preventive, curative and rehabilitative aspects of care related to maternal, newborn and child health, malaria, tuberculosis, HIV/AIDs as well as other communicable and non-communicable diseases" [26] (pg. 8). However with this expansive role, we recognize the need to support these local workers, with funding, transport, and education [26].

\section{Limitations}

This is a pilot feasibility study with a small sample size and only reports results from one rural district in NorthWest Tanzania. Additionally, as noted in the Data Collection section, all cooking fuel use is self-reported although the CTW could monitor LPG refills. Thus, our results are vulnerable to recall bias. Our results are also vulnerable to social desirability bias; however, in all surveys and interviews, we reminded the participant that we simply wanted to understand barriers to LPG use and appreciated their honesty regarding their biomass use and experience with the pilot. Over the study period, on average $\sim 40 \%$ of households were using LPG exclusively indicating that this model is insufficient to address all the barriers to exclusive clean fuel use. We acknowledge that we are unable to isolate the effect of the CTW. Barriers to continued technology use overlap and cover a range of disciplines, and thus may be best addressed together. Further research into this model with differing levels of visits or engagement could help isolate the CTW's effect.

\section{Conclusions}

The results that $80 \%$ of households refilled throughout the study and $\sim 40 \%$ became exclusive LPG users suggest that this outreach model could be a mechanism to increase rates of LPG use. This is a particularly high rate of exclusive use considering the availability of free firewood. The CTW was found to address a range of barriers facing the households including lack of education, behavior change challenges, financial hardships, and even water purification. Our results indicate that local outreach is necessary, yet insufficient to achieve $100 \%$ exclusive use. Our results encourage a partnership of the CTW model with the private LPG sector and or a microsavings program to ameliorate affordability issues. Social and economic support are critical to achieving exclusive LPG use. Community based outreach is invaluable in any transition, but especially to increase the continued use of clean energy for cooking and beyond.

\section{Supplementary Information}

The online version contains supplementary material available at https://doi. org/10.1186/s13705-022-00331-x.

Additional file 1. Supplemental Material: Appendices.

\section{Acknowledgements}

We would like to first thank Nayome Aguttu and Mary Frances as without their excellent work and expertise as Community Technology Workers this project would not have been possible. We would also like to thank Fred Chacha, the In-Country Director of ReachShirati for the logistical support throughout my two summers in Shirati and throughout the pilot. We are grateful to each and every household in the pilot that offered their time and opened their families to this research team. We would like to thank Mama Randa for feeding and housing Gill-Wiehl for both summers. We also thank Luke Maillie for his friendship, advice and for connecting us to ReachShirati and the Shirati community. We'd specifically like to acknowledge Holly Rivers and Rachel Thiel for their support and guidance at the Kellogg Institute. We thank Bodie Cabiyo and Isa Ferral for their insightful comments on drafts of this work. AGW thanks Dr. Isha Ray for additional advising support. Finally, we thank two anonymous reviewers who provided thorough and thoughtful feedback on this work.

\section{Authors' contributions}

AGW and SS designed the research and conducted the analysis. AGW and DK developed the discussions and wrote the manuscript. All authors read and approved the final manuscript.

\section{Funding}

This work was supported by the Kellogg Institute for International Studies at the University of Notre Dame under a Summer Research Grant. We gratefully acknowledge support from a NRT training grant from the National Science Foundation Innovation in Food, Energy, Water systems program (NSF-1633740).

\section{Availability of data and materials}

The datasets used and/or analyzed during the current study are available from the corresponding author on reasonable request. 


\section{Declarations}

Ethics approval and consent to participate

This work was approved under Exempt Research under the University of Notre Dame's IRB Protocol ID: 18-02-4425.

\section{Consent for publication}

Not applicable.

\section{Competing interests}

The authors declare no competing financial interest.

\section{Author details}

'Energy and Resources Group, University of California, 345 Giannini Hall, Berkeley, CA 94720, USA. ${ }^{2}$ Goldman School of Public Policy, University of California, Berkeley, CA 94720, USA. ${ }^{3}$ Kellogg Institute for International Studies, University of Notre Dame, Notre Dame, IN 46556, USA. ${ }^{4}$ Keough School of Global Affairs, University of Notre Dame, Notre Dame, IN 46556, USA.

Received: 18 March 2021 Accepted: 3 January 2022

Published online: 13 January 2022

\section{References}

1. IEA, IRENA, UNSD, et al (2019) Tracking SDG 7: the Energy Progress Report 2019. Washington DC. https://trackingsdg7.esmap.org/

2. Dhimal M, Chirico F, Bista B et al (2021) Impact of air pollution on global burden of disease in 2019. Lancet Glob Heal 9:1-9. https://doi.org/10. 3390/pr9101719

3. Bond TC, Doherty SJ, Fahey DW et al (2013) Bounding the role of black carbon in the climate system: a scientific assessment. J Geophys Res Atmos 118:5380-5552. https://doi.org/10.1002/jgrd.50171

4. Bailis R, Drigo R, Ghilardi A, Masera O (2015) The carbon footprint of traditional woodfuels. Nat Clim Chang 5:266-272. https://doi.org/10.1038/ nclimate2491

5. Clean Cooking Alliance (2019) Tanzania. https://www.cleancookingall iance.org/country-profiles/41-tanzania.html. Accessed 30 Oct 2019

6. Van Leeuwen R, Evans A, Hyseni B (2017) Increasing the use of liquefied petroleum gas in cooking in developing countries. World Bank Live Wire. Washington, DC. https://openknowledge.worldbank.org/handle/10986/ 26569

7. Bruce NG, Aunan K, Rehfuess EA, Development Bank K (2017) Liquefied petroleum gas as a clean cooking fuel for developing countries: implications for climate, forests, and affordability materials on development financing | KfW Development Bank-Materials on Development Financing, No. 72 Content. https://www.kfw-entwicklungsbank.de/PDF/DownloadCenter/Materialien/2017_Nr.7_CleanCooking_Lang.pdf

8. Bailis R, Ezzati M, Kammen DM (2005) Mortality and greenhouse gas impacts of biomass and petroleum energy futures in Africa. Science 308:98-103

9. (2019) Report No.14 of 2019: Performance Audit of Pradhan Mantri Ujjawala Yojana, Ministry of Petroleum and Natural Gas. https://cag.gov. in/content/report-no14-2019-performance-audit-pradhan-mantri-ujiwa la-yojana-ministry-petroleum-and

10. Jain A, Tripathi S, Mani S, et al (2018) Access to clean cooking energy and electricity survey of states 2018. India's Council for Energy, Environment, and Water. New Delhi.

11. Indian Ministry of Petroleum and Natural Gas (2018) LPG Profile (Data on LPG Marketing as on 01.07.2018). www.ppac.org.in

12. Čukić I, Kypridemos C, Evans AW et al (2021) Towards sustainable development goal 7 "universal access to clean modern energy": National strategy in Rwanda to scale clean cooking with bottled gas. Energies. https://doi.org/10.3390/en14154582

13. Bawakyillenuo S, Crentsil AO, Innocent K et al (2021) Intention for change The landscape of energy for cooking in Ghana: a review. MECS. https:// mecs.org.uk/

14. United Republic of Tanzania (2019) Tanzania Mainland. Key Indicators Report 2017-2018 Household Budget Survey
15. Budya $H$, Arofat M (2011) Providing cleaner energy access in Indonesia through the megaproject of kerosene conversion to LPG. Energy Policy 39:7575-7586. https://doi.org/10.1016/j.enpol.2011.02.061

16. Asante KP, Afari-Asiedu S, Abdulai MA et al (2018) Ghana's rural liquefied petroleum gas program scale up: a case study. Energy Sustain Dev 46:94-102. https://doi.org/10.1016/j.esd.2018.06.010

17. Hollada J, Williams KN, Miele CH et al (2017) Perceptions of improved biomass and liquefied petroleum gas stoves in Puno, Peru: implications for promoting sustained and exclusive adoption of clean cooking technologies. Int J Environ Res Public Health 14:182. https://doi.org/10.3390/ ijerph14020182

18. Hsu E, Gan M, Puzzolo E (2019) Microfinance for clean cooking What lessons can be learned for scaling up LPG adoption in Kenya through managed loans?

19. Budya H, Arofat M, Yasir Arofat M (2011) Providing cleaner energy access in Indonesia through the megaproject of kerosene conversion to LPG. Energy Policy 39:7575-7586. https://doi.org/10.1016/j.enpol.2011.02.061

20. Kimemia D, Annegarn H (2016) Domestic LPG interventions in South Africa: challenges and lessons. Energy Policy 93:150-156. https://doi.org/ 10.1016/j.enpol.2016.03.005

21. Nexant I (2005) LPG Market Assessment Study for Mozambique. USAID. Washington D.C. https://pdf.usaid.gov/pdf_docs/Pnadg948.pdf

22. ESMAP (2005) Pilot Commercialization of Improved Cookstoves in Nicaragua. https://esmap.org/

23. Gould CF, Hou X, Richmond J et al (2020) Jointly modeling the adoption and use of clean cooking fuels in rural India. Environ Res Commun. https://doi.org/10.1088/2515-7620/abaca9

24. Ronzi S, Puzzolo E, Hyseni L et al (2019) Using photovoice methods as a community-based participatory research tool to advance uptake of clean cooking and improve health: the LPG adoption in Cameroon evaluation studies. Soc Sci Med 228:30-40. https://doi.org/10.1016/j.socscimed. 2019.02.044

25. Rai K, McDonald J (2009) Cookstoves and markets: experiences, successes and opportunities

26. Bhutta ZA, Lassi ZS, Pariyo G, Huicho L Global evidence of community health workers global experience of community health workers for delivery of health related millennium development goals: a systematic review, country case studies, and recommendations for integration into national health systems

27. Lehmann U, Sanders D (2007) Community health workers: what do we know about them? Geneva

28. Tani K, Stone A, Exavery A et al (2016) A time-use study of community health worker service activities in three rural districts of Tanzania (Rufiji, Ulanga and Kilombero). BMC Health Serv Res. https://doi.org/10.1186/ s12913-016-1718-6

29. Mpembeni RNM, Bhatnagar A, LeFevre A et al (2015) Motivation and satisfaction among community health workers in Morogoro Region, Tanzania: nuanced needs and varied ambitions. Hum Resour Health. https:// doi.org/10.1186/s12960-015-0035-1

30. Rafiq MY, Wheatley H, Mushi HP, Baynes C (2019) Who are CHWs? An ethnographic study of the multiple identities of community health workers in three rural Districts in Tanzania. BMC Health Serv Res. https://doi.org/ 10.1186/s12913-019-4563-6

31. Barstow CK, Ngabo F, Rosa G et al (2014) Designing and piloting a program to provide water filters and improved cookstoves in Rwanda. PLoS ONE. https://doi.org/10.1371/journal.pone.0092403

32. Perry H, Criglers L, Hodgins S (2013) Developing and strengthening community health worker programs at scale: a reference guide for program managers and policy makers

33. Pye A, Ronzi S, Ngahane BHM et al (2020) Drivers of the adoption and exclusive use of clean fuel for cooking in Sub-Saharan Africa: learnings and policy considerations from Cameroon. Int J Environ Res Public Health. https://doi.org/10.3390/ijerph17165874

34. Bruce N, de Cuevas RA, Cooper J et al (2018) The Government-led initiative for LPG scale-up in Cameroon: programme development and initial evaluation. Energy Sustain Dev 46:103-110. https://doi.org/10.1016/i.esd. 2018.05.010

35. Hsu E, Forougi N, Gan M et al (2021) Microfinance for clean cooking: what lessons can be learned for scaling up LPG adoption in Kenya through managed loans? Energy Policy 154:112263. https://doi.org/10.1016/j. enpol.2021.112263 
36. Masera OR, Saatkamp BD, Kammen DM (2000) From linear fuel switching to multiple cooking strategies: a critique and alternative to the energy ladder model. Pergamon

37. Arnold JE, Jongma J (1978) Fuelwood and charcoal in developing countries: an economic survey

38. Loeliger KB, Niccolai LM, Mtungwa LN et al (2016) "I Have to Push Him with a Wheelbarrow to the Clinic": community Health Workers' Roles, Needs, and Strategies to Improve HIV Care in Rural South Africa. AIDS Patient Care STDS 30:385-394. https://doi.org/10.1089/apc.2016.0096

39. Nxumalo N, Goudge J, Thomas L (2013) Outreach services to improve access to health care in South Africa: lessons from three community health worker programmes. Glob Health Action 6:19283. https://doi.org/ 10.3402/gha.v6i0.19283

40. United Republic of Tanzania (2016) National Accounts of Tanzania Mainland 2007-2015. Dar es Salaam

41. Cabiyo B, Ray I, Levine DI (2021) The refill gap: clean cooking fuel adoption in rural India OPEN ACCESS The refill gap: clean cooking fuel adoption in rural India

42. Gill-Wiehl A, Ray I, Kammen D (2021) Is clean cooking affordable? A review. Renew Sustain Energy Rev 151:111537. https://doi.org/10.1016/j. rser.2021.111537

43. Envirofit (2015) Cooking in one million kitchens: lessons learned in scaling a clean Cookstove Business

44. Jennings L, Ong Ech J, Simiyu R et al (2013) Exploring the use of mobile phone technology for the enhancement of the prevention of mother-tochild transmission of HIV program in Nyanza, Kenya: a qualitative study. BMC Public Health. https://doi.org/10.1186/1471-2458-13-1131

45. Surka S, Edirippulige S, Steyn K et al (2014) Evaluating the use of mobile phone technology to enhance cardiovascular disease screening by community health workers. Int J Med Inform 83:648-654. https://doi.org/10. 1016/j.jjmedinf.2014.06.008

46. Mahmud N, Rodriguez J, Nesbit J (2010) A text message-based intervention to bridge the healthcare communication gap in the rural developing world. Technol Health Care 18:137-144. https://doi.org/10.3233/ THC-2010-0576

47. Angelou N, Bhatia M (2015) Beyond connections: energy access Redefined. Washington DC

\section{Publisher's Note}

Springer Nature remains neutral with regard to jurisdictional claims in published maps and institutional affiliations.

Ready to submit your research? Choose BMC and benefit from:

- fast, convenient online submission

- thorough peer review by experienced researchers in your field

- rapid publication on acceptance

- support for research data, including large and complex data types

- gold Open Access which fosters wider collaboration and increased citations

- maximum visibility for your research: over $100 \mathrm{M}$ website views per year

At BMC, research is always in progress.

Learn more biomedcentral.com/submissions 